\title{
ANALYSIS OF THE POSSIBILITIES OF USING LOW-COST SCANNING SYSTEM IN 3D MODELING
}

\author{
M. Kedzierski ${ }^{a}$, D. Wierzbicki ${ }^{\text {** }}$, A. Fryskowska ${ }^{a}$, B. Chlebowska ${ }^{a}$ \\ ${ }^{\text {a }}$ Department of Remote Sensing and Photogrammetry, Institute of Geodesy, Faculty of Civil Engineering and Geodesy, Military \\ University of Technology, 2 gen. Sylwestra Kaliskiego st., 00-908 Warsaw, Poland \\ (michal.kedzierski, damian.wierzbicki,, anna.fryskowska,@wat.edu.pl; beatabrzozowska1991@o2.pl)
}

Commission III, WG III/2

KEY WORDS: Photogrammetry, Laser scanning, Point Cloud, Building modeling, Accuracy

\begin{abstract}
:
The laser scanning technique is still a very popular and fast growing method of obtaining information on modeling 3D objects. The use of low-cost miniature scanners creates new opportunities for small objects of 3D modeling based on point clouds acquired from the scan. The same, the development of accuracy and methods of automatic processing of this data type is noticeable. The article presents methods of collecting raw datasets in the form of a point-cloud using a low-cost ground-based laser scanner FabScan. As part of the research work 3D scanner from an open source FabLab project was constructed. In addition, the results for the analysis of the geometry of the point clouds obtained by using a low-cost laser scanner were presented. Also, some analysis of collecting data of different structures (made of various materials such as: glass, wood, paper, gum, plastic, plaster, ceramics, stoneware clay etc. and of different shapes: oval and similar to oval and prism shaped) have been done. The article presents two methods used for analysis: the first one - visual (general comparison between the 3D model and the real object) and the second one - comparative method (comparison between measurements on models and scanned objects using the mean error of a single sample of observations). The analysis showed, that the low-budget ground-based laser scanner FabScan has difficulties with collecting data of non-oval objects. Items built of glass painted black also caused problems for the scanner. In addition, the more details scanned object contains, the lower the accuracy of the collected point-cloud is. Nevertheless, the accuracy of collected data (using oval-straight shaped objects) is satisfactory. The accuracy, in this case, fluctuates between $\pm 0,4 \mathrm{~mm}$ and $\pm 1,0 \mathrm{~mm}$ whereas when using more detailed objects or a rectangular shaped prism the accuracy is much more lower, between $2,9 \mathrm{~mm}$ and $\pm 9,0 \mathrm{~mm}$. Finally, the publication presents the possibility (for the future expansion of research) of modernization FabScan by the implementation of a larger amount of camera-laser units. This will enable spots the registration, that are less visible.
\end{abstract}

\section{INTRODUCTION}

Within last years, the scanning laser became a very popular measurement technique that allows quick, precise, and noninvasive collection of 3D information about the objects (Kedzierski, Fryskowska, 2015; Kedzierski, Fryskowska, 2014; Kedzierski et al., 2010). There are many definitions on laser scanning. According to Brockhouse (Brockhouse, 1986), laser scanning is a point data collection in order to identify the geometry of the object with use of special technical equipment. By determining the measurements as ,point" we understand the relatively large density of points, which through the automatic mode of measurements results in their uniform location and enables the measurement without signaling of the points. More frequently is also observed the miniaturization of the scanners that collect the spatial information about the 3D objects. An example of such miniaturized scanner is FabScan scanner, elaborated and constructed within a FabLab project. The idea of the project is the propagation of the society active approach through carrying the activities with „,do-it-yourself” idea, open software, open technologies, and self-sufficiency in harmony with the natural environment, culture benefit- using both, the latest and old solutions. The main aim of the research work was to collect the data in the form of raw clouds of the points using low-budget ground laser scanner FabScan. For this aim, everyday use things were used: ceramic mug, glass bottle of perfumes in different shapes, paper bag, and decorative things: miniature toy and figures made of stoneware.

The leading problem of this article was making an attempt to construct a low-budget ground laser scanner FabScan from the FabLab project, so that in result it would be possible to carry the analysis of the possibility of data collection.

The research work focuses on:

- $\quad$ The assembly procedure of particular parts during FabScan laser construction

- The specificity of obtained clouds of point for the above-mentioned objects

- Possibility of data processing using MeshLab software and its functions

- Analysis of the obtained data

The article was summarized with conclusions that result from carrying the research experiment.

\section{EXPERIMENT}

The analysis is based on results of the measurements made with low-budget ground laser scanner FabScan. That is why, the following subsections present the technical specification of the

\footnotetext{
* Corresponding author - Damian Wierzbicki, damian.wierzbicki@ wat.edu.pl, +48 261839291
} 
device, accuracy and scanning resolution, and also the way of functioning.

\subsection{Technical specification of FabScan scanner}

FabScan scanner has a possibility to scan objects of size 14 $\mathrm{cm} 14 \mathrm{~cm} \times 15 \mathrm{~cm}$, with scanning resolution from $0,1 \mathrm{~mm}$ to 0,2 $\mathrm{mm}$. The scanner uses a laser with wavelength $65 \mathrm{~nm}$ and $5 \mathrm{~mW}$ power. The scanner works with energy supply $12 \mathrm{~V}$. An attractive characteristic of the device is not large size $(32 \mathrm{~cm} \mathrm{x}$ $30 \mathrm{~cm}$ x $29 \mathrm{~cm}$ ) weight $1,8 \mathrm{~kg}$ (Fig. 1).

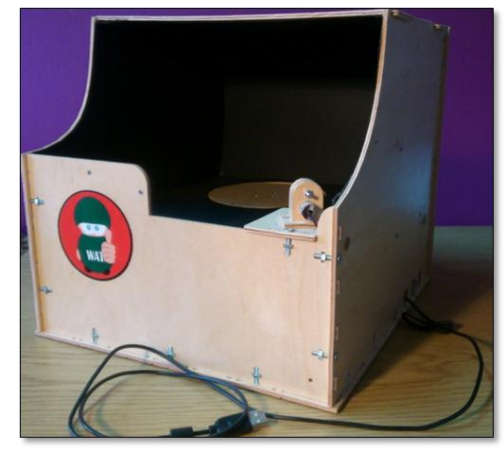

Figure 1. FabScan scanner

\begin{tabular}{|l|l|}
\hline Model & FabScan \\
\hline Scanner type & $\begin{array}{l}\text { Low-budget ground laser } \\
\text { scanner }\end{array}$ \\
\hline Scanning volume & $14 \mathrm{~cm} \mathrm{x} 14 \mathrm{~cm} \mathrm{x} 15 \mathrm{~cm}$ \\
\hline Scanning resolution & $0,1 \mathrm{~mm}-0,2 \mathrm{~mm}$ \\
\hline Power & $12 \mathrm{~V}$ \\
\hline Laser parameters & wavelength $655 \mathrm{~nm}$ output $5 \mathrm{~mW}$ \\
\hline Weight & $1,8 \mathrm{~kg}$ \\
\hline Size & $32 \mathrm{~cm} \times 30 \mathrm{~cm} \mathrm{\times} 29 \mathrm{~cm}$ \\
\hline
\end{tabular}

Table 1. Basic technical parameters of FabScan scanner

\subsection{Scanning accuracy}

The accuracy of the low-budget scanner was determined on the basis of two known objects. First, the objects were scanned, and next compared with their physical size. The physical size of the objects was measured with vernier calliper gauge. However, the size of the digital models was determined in MashLab software (Corsini and Ranzuglia, 2008), using measuring tools. The creators of FabLab emphasize that determining the size of the objects in the environment requires little practice for the measurement to be determined precisely. Hence, the accuracy measurement may have little errors.

The first object scanned for the accuracy analysis was cut cone made of white polystyrene, the second object was a figure of a bear. In the case of the bear figure, the values for the analysis were measured with vernier calliper gauge also on the retort made with 3D printer as a result of the Fabscan scanner product (scanned cloud of points of the bear figure). It has to be emphasized that the minimal resolution of $3 \mathrm{D}$ printers in the printing layer is $0,1778 \mathrm{~mm}$, what increases the measurement error in the retorts. The results of the measurements are presented in Figure 2. For the original figure of the bear, there was measured a distance between nose and tail and it amounted $101,6 \mathrm{~mm}$. However, the same distance in the retort was 100,7 $\mathrm{mm}$, what have $0,9 \mathrm{~mm}$ difference.

(Engelmann, 2011).

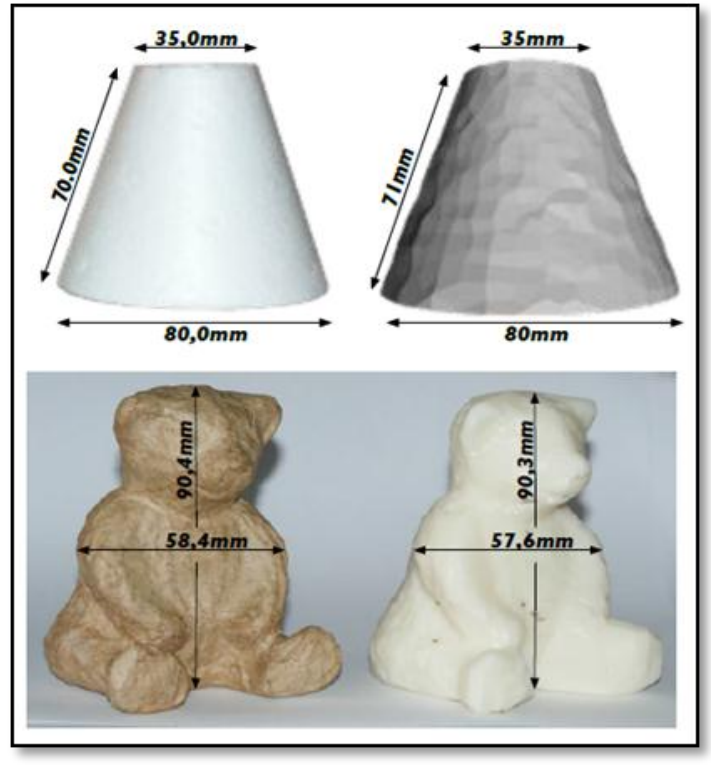

Figure 2. Comparison of the real object (left side) and retort (right side) (Engelmann, 2011)

\begin{tabular}{|c|c|c|c|}
\hline Cut cone & $\begin{array}{c}\text { Physical } \\
\text { value } \\
\text { [mm] }\end{array}$ & $\begin{array}{c}\text { Value in } \\
\text { MashLab } \\
\text { model } \\
\text { [mm] }\end{array}$ & $\begin{array}{c}\text { Difference } \\
\text { [mm] }\end{array}$ \\
\hline $\begin{array}{c}\text { Small } \\
\text { diameter }\end{array}$ & 35,00 & 35,00 & 0,00 \\
\hline $\begin{array}{c}\text { Large } \\
\text { diameter }\end{array}$ & 70,00 & 70,00 & 0,00 \\
\hline Side & 80,00 & 80,00 & 0,00 \\
\hline $\begin{array}{c}\text { Bear } \\
\text { figure }\end{array}$ & $\begin{array}{c}\text { Physical } \\
\text { value } \\
\text { [mm] }\end{array}$ & $\begin{array}{c}\text { 3D print } \\
\text { value } \\
\text { [mm] }\end{array}$ & $\begin{array}{c}\text { Difference } \\
{[\mathbf{m m}]}\end{array}$ \\
\hline Height & 90,4 & 90,3 & 0,1 \\
\hline Width & 58,4 & 57,6 & 0,8 \\
\hline $\begin{array}{c}\text { Distance } \\
\text { from nose } \\
\text { to tail }\end{array}$ & 101,6 & 100,7 & 0,9 \\
\hline
\end{tabular}

Table 2. Comparison of results of the objects measurements

In table 2 we can observe some dependencies, namely the divergences between the size of the object and its printed retort (bear figure), that do not exceed $1 \mathrm{~mm}$, and also the same measurements of the physical object (cone) and its model. The evaluation of the scanning accuracy is dependent on the appointment and aim of the scan, or the demand for the 3D print product.

\subsection{Scanning resolution}

Maximum resolution of the scanner (minimal distance between two points in the cloud of points) is dependent on the current distance between the scanned object, camera, and laser, and also the location of the object on the rotary table.

Additionally, the horizontal and vertical has to be distinguished. The vertical resolution is dependent on the step size of the stepper motor, where the minimal step size equals $0,1225^{\circ}$. The vertical resolution is not limited by the rotation of the platform because the laser beam is a continuous vertical line. Moreover, both resolutions are influenced by the camera. 
Common internet cameras used for assembly of scanner like FabScan have a resolution of $1600 \rightarrow 1200$ pixels. In the analysis of the vertical and horizontal resolution, it was established that pixel is a square. The scanner resolution increases together with moving the object on the platform near to the camera. So, to measure the maximum resolution of the device, points were chosen on the minimal distance between the camera and object on the platform. In such a position, $15 \mathrm{~cm}$ responded 1500 pixel. Hence, 1 pixel is $0,1 \mathrm{~mm}$. For comparison, a maximum distance was measured between the camera and object on the opposite side of the rotary platform, what in result gave resolution equal $0,2 \mathrm{~mm}$. In effect, the estimated resolution is from $0,1 \mathrm{~mm}$ to $0,2 \mathrm{~mm}$ (in the center of the rotary table $0,149 \mathrm{~mm}$ ) (Engelmann, 2011).

\subsection{Characteristics of the scanning system}

The system of ground laser scanner usually consists of a transmitter, i.e. module generating the laser light (diode), the system of rotating mirrors. Their task is to balance the angle deflexion (vertical and horizontal) of the laser beam and its dispersion on the surface of the objects, optic telescope that converges the returning reflected radiation.

In case of a complex low-budget ground laser scanner, the system is simplified. It consists of transmitter- the laser, and the camera that registers the returning reflected rays. The position of the laser and the camera are of known construction, the same as the reflection position of the laser line from the back wall of the scanner. The camera registers the beam of light reflected from the surface of the object what is later processed from the surface of the picture in the local system. Figure 3 presents the diagram of the FabScan scanning system. This diagram adapts the approximation of the laser beam located at a suitable distance from the object, as a plain surface in space, establishing that the angle of opening the lens of the laser is large enough to take the scanned object. The camera registers the cut of the laser beam plane with the scanned object, what makes the lit bends on the object (the red line on the drawing)so called segments. These segments are made of many lit points. A single bright point visible through the camera determined the radius of the camera (Fig. 3) (Engelmann, 2011).

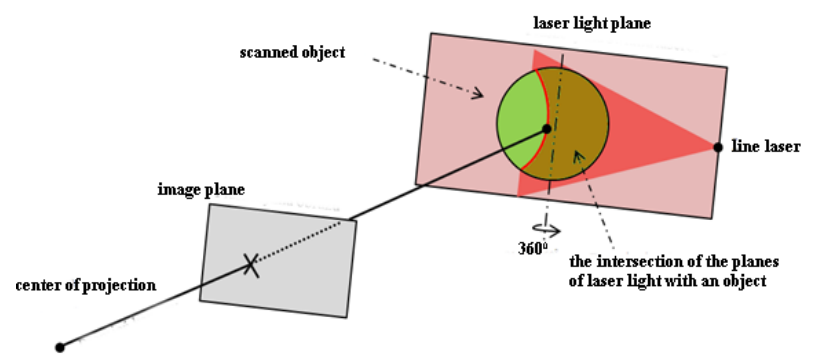

Figure 3. The scanning scheme of the FabScan scanner

Within the assumption that the position of the laser and the camera are known (and constant), there can be also calculated the equation of the plane of the laser beam, and also the equation of the camera radium responding to lit points on the object. The position of the lit points is designated by the cross of the laser beam plane with camera radius. Through the rotation of the object by $360^{\circ}$ during the scanning process, all the sides of the object are lit. It makes obtaining the $3 \mathrm{D}$ model possible (Lanman, Taubin, 2009).

\section{GEOMETRY OF THE CLOUD OF POINTS}

This part presents the issue of the geometry of the obtained cloud of points using low-budget ground laser scanner FabScan according to the theory of Francis Engelmann, the author of the article „FabScan Affordable 3D Laser Scanning of Physical Objects", who, when discussing this subject made the following assumptions:

- Location of the elements: location of the laser emitting the beam and the camera is known and constant

- The line of the laser is ideally vertical

- The camera is ideally perpendicular to the back wall of the scanner

Because of the above-presented assumptions, the geometric model of the scanning system does not lose a lot of precision, because the errors are relatively small, that is why in the calculations the mathematical simplifications are used.

Based on these assumptions, all the points in the cloud of points can be displayed on one horizontal plane what allows to move the object from $3 \mathrm{D}$ dimension to $2 \mathrm{D}$. This situation is presented in Figure 4. This simplification means loss of information about the height (because the 2D dimension has the coordinates of $\mathrm{X}, \mathrm{Y}$ points). This loss is temporary because it can be entered again, what will be discussed later. This simplification results from the difficulty of designating the intersection of the planes in the 3D dimension. That is why, a temporary transformation to 2D was made, to designate the intersection of two lines (Fig. 4).

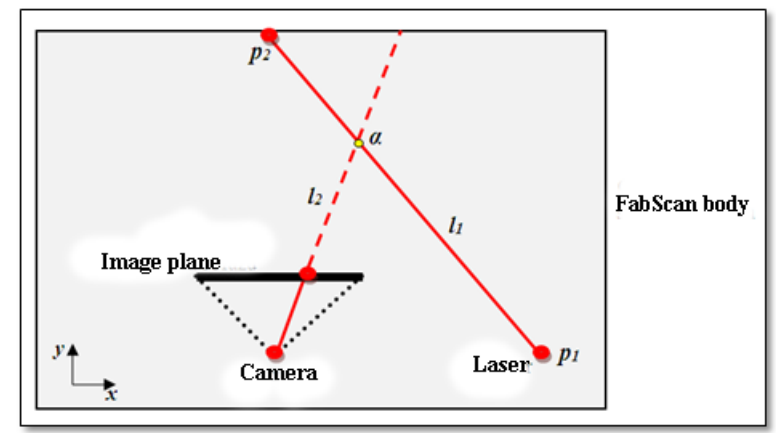

Figure 4. Intersection of the beams inside the scanner (2D dimension)

On the basis of two known points, $p_{1}$ and $p_{2}$, we can designate the equation of the (straight) line $l_{l}$. Equation of the straight line in the $2 \mathrm{D}$ dimension is defined by:

$$
y=a \cdot x+b
$$

These points are represented by the pairs of coordinates $p=\left(x_{p}, y_{p}\right)$. Hence, straight line $l_{l}$ is determined by the equation:

$$
l_{l} \equiv y=a_{l} \cdot x+b
$$

Where parameter $a_{l}$, depending on the points $p_{1}$ and $p_{2}$ takes the form:

$$
a_{1}=\frac{\Delta y}{\Delta x}=\frac{\left(y_{p 2}-y_{p 1}\right)}{\left(x_{p 2}-x_{p 1}\right)}
$$

By substituting the point $p_{1}$ ( or $p_{2}$ ) to the formula (2), parameter $b_{l}$ can be determined: 


$$
b_{1}=y_{p 1}-a_{1} \cdot x_{p 1}
$$

In results, a complete equation of straight line $l_{l}$ was obtained. The same procedure was repeated in order to deisgnate straight line $l_{2}$. Knowing the equations of two lines $l_{1}$ and $l_{2}$, their intersection $\alpha$ was calculated.

$$
\begin{gathered}
l_{l}=l_{2} \\
\leftrightarrow a_{1} \cdot x_{\alpha}+b_{1}=a_{2} \cdot x_{\alpha}+b_{2} \\
\leftrightarrow x_{a}=\frac{b 2-b 1}{a 1-a 2}
\end{gathered}
$$

$$
\text { where } a_{1} \neq a_{2}
$$

Analogically, designating $\mathrm{y}_{\alpha}$ consists of substituting $\alpha$ to the equation (2):

$$
y_{\alpha}=a_{1} \cdot x_{\alpha}+b_{1}
$$

Now when the real location of the points of the scanned object is known in the local system (distance from camera), the algorithm scales the height that was omitted on purpose during the change of dimensions from $3 \mathrm{D}$ to $2 \mathrm{D}$, because, designating the points only creates a flat picture of the object. However, considering its height presents its $3 \mathrm{D}$ representation.

These measurements are repeated for every point of the laser beam reflection from the object surface. The designated set of points is subjected to the conversion of the affine transformation in order to consider the rotary movement of the platform on which the object is placed during the scanning.

\section{RESULTS}

In this part, there were presented the results of the accuracy analysis of the data obtained from the low-budget ground scanner. The analysis was made at an angle of the resolution of the cloud of points possible to obtain with the use of this device, and also at comparison angle of the distance measured on the original objects and their models.

\subsection{Analysis of the FabScan scanner resolution}

The first analysis was research on the resolution of the FabScab scanner. The choice of the resolution decides about the accuracy of the obtained data. FabScan software which is an integral part of the scanner offers four types of the resolution quality: the best, good, normal, and poor (Fig. 5).
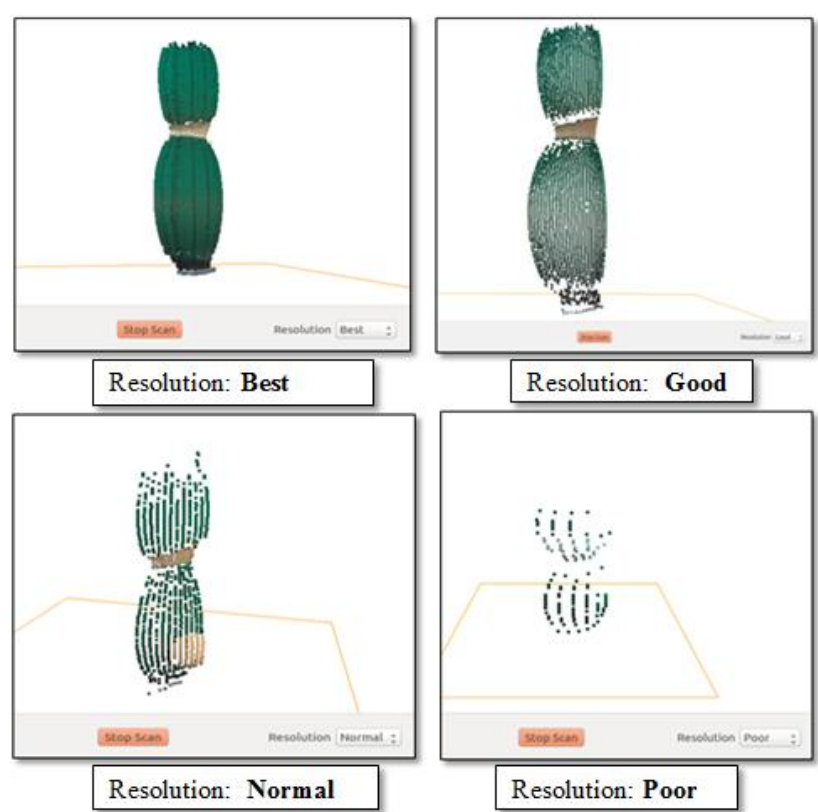

Figure 5. Visual comparison analysis of the cloud of points resolution

First of all, there was made a visual comparison analysis of the cloud of points on the fragment of the same object (Fig. 5). As it is visible in the picture, as the quality of the resolution is weaker, the cloud of points is more tenuous and less detailed. Namely, the segment (a visible line of the scanner scanning) from the segment of the cloud of points, and also from point to point in the segment in the larger distance. This resolution is understood as an average distance between the points in the

\begin{tabular}{|c|c|c|c|c|}
\hline \multirow[b]{2}{*}{ Measurement } & \multicolumn{4}{|c|}{$\begin{array}{l}\text { Horizontal distance between the points } \\
{[\mathrm{mm}]}\end{array}$} \\
\hline & Best & Good & Normal & Poor \\
\hline 1 & 0,31 & 0,12 & 0,71 & 1,50 \\
\hline 2 & 0,29 & 0,31 & 0,92 & 1,56 \\
\hline 3 & 0,49 & 0,33 & 0,85 & 1,52 \\
\hline 4 & 0,22 & 0,17 & 0,81 & 1,59 \\
\hline 5 & 0,13 & 0,34 & 0,91 & 1,59 \\
\hline 6 & 0,28 & 0,19 & 0,98 & 1,55 \\
\hline 7 & 0,14 & 0,21 & 0,83 & 1,49 \\
\hline 8 & 0,14 & 0,35 & 0,88 & 1,51 \\
\hline 9 & 0,29 & 0,13 & 0,87 & 1,51 \\
\hline 10 & 0,14 & 1,56 & 0,58 & 1,51 \\
\hline $\begin{array}{l}\text { Average } \\
\text { resolution of } \\
\text { the cloud of } \\
\text { points [mm] }\end{array}$ & 0,24 & 0,37 & $\mathbf{0 , 8 3}$ & 1,53 \\
\hline
\end{tabular}
given plane of the object that was determined by the statistical analysis of the measurement of the vertical and horizontal distance in 10 places. In result of it, there was obtained a particularization to horizontal (Tab.3) and vertical (Tab. 4) resolutions.

Table 3. Determining the vertical resolution 


\begin{tabular}{|c|c|c|c|c|}
\hline \multirow{2}{*}{ Measurement } & \multicolumn{4}{|c|}{$\begin{array}{c}\text { Horizontal distance between the points } \\
\text { [mm] }\end{array}$} \\
\cline { 2 - 5 } & Best & Good & Normal & Poor \\
\hline 1 & 0,04 & 1,25 & 1,98 & 6,35 \\
\hline 2 & 0,04 & 1,29 & 1,82 & 5,83 \\
\hline 3 & 0,04 & 1,31 & 1,97 & 4,49 \\
\hline 4 & 0,04 & 1,30 & 2,06 & 7,15 \\
\hline 5 & 0,04 & 1,34 & 2,01 & 6,14 \\
\hline 6 & 0,04 & 1,21 & 1,81 & 5,94 \\
\hline 7 & 0,04 & 1,23 & 1,86 & 5,23 \\
\hline 8 & 0,04 & 1,29 & 1,94 & 5,85 \\
\hline 9 & 0,04 & 1,29 & 1,94 & 5,93 \\
\hline 10 & 0,04 & 1,24 & 1,97 & 6,39 \\
\hline $\begin{array}{l}\text { Average } \\
\text { resolution of } \\
\text { the cloud of } \\
\text { points [mm] }\end{array}$ & $\mathbf{0 , 0 4}$ & $\mathbf{1 , 2 7}$ & $\mathbf{1 , 9 4}$ & $\mathbf{5 , 9 3}$ \\
\hline & & & & \\
\hline
\end{tabular}

Table 4. Designating the horizontal resolution

Analyzing the above-given tables (Tab. 3 and Tab. 4), it can be Stated that the highest vertical and horizontal quality had the cloud with the best scanning quality. Both, the horizontal and vertical resolutions do not exceed $1 \mathrm{~mm}$ (respectively, they have $0,04 \mathrm{~mm}$ and $0,24 \mathrm{~mm}$ ). However, the lowest resolution was obtained for the poor quality, where both values are more than 1 $\mathrm{mm}$ (respectively: $1,53 \mathrm{~mm}$ and $5,93 \mathrm{~mm}$ ). The obtained values of the researched resolutions are different in relation to the resolutions determined with other methods using FabScan scanner with the same parameters by Francis Engelmann, the author of the article „FabScan Affordable 3D Laser Scanning of Physical Objects". Engelmann estimated the resolution values on the basis of the distance between the object and the camera, and also the resolution of the camera, in result of which he obtained a result $0,1-0,2 \mathrm{~mm}$, however in the work these values are similar only to the scanning with the best resolution quality $(0,24 \mathrm{~mm} ; 0,04 \mathrm{~mm})$, which is impractical. However, the other qualities with their resolution values are many times higher than those showed by Engelmann.

\subsection{Analysis of the possibility of data collection}

The second carried analysis was a visual analysis of the possibility of collecting the data from the scanned objects made of different materials and of different shapes.

To the research were subjected such objects as:
a) spongiform mascot
b) glass bottle of perfumes,
c) plastic water container,
d) figure of a snail
e) ceramic mug,
f) paper box

The first scanned object was the oval-shaped spongiform mascot. The toy has a simple construction that was correctly scanned and modeled. The effects of the data collection are given by the photos below (Fig. 6)
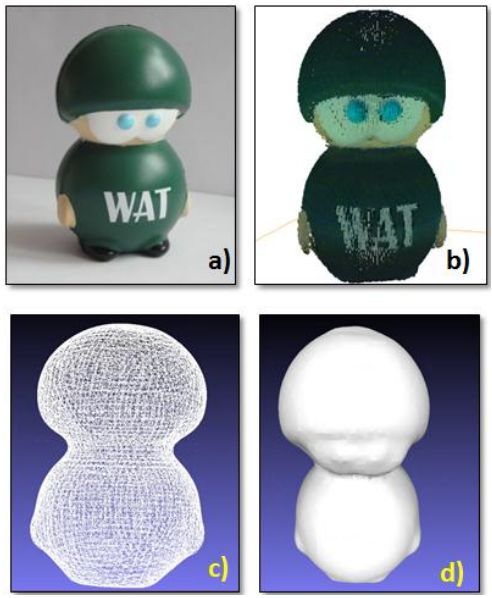

Figure 6. Spongiform mascot of WAT university: a) photo of the real object; b) scanned cloud of points; c) processed data in form of TIN surface d) 3D model

The next subject of the analysis was glass bottle of perfumes with a different type of glass. During the scanning, it was observed that the glass objects are hard to scan correctly because the glass reflects the light. Figure 7 shows an unsuccessful attempt of scanning the flacon and its smooth glass surface.
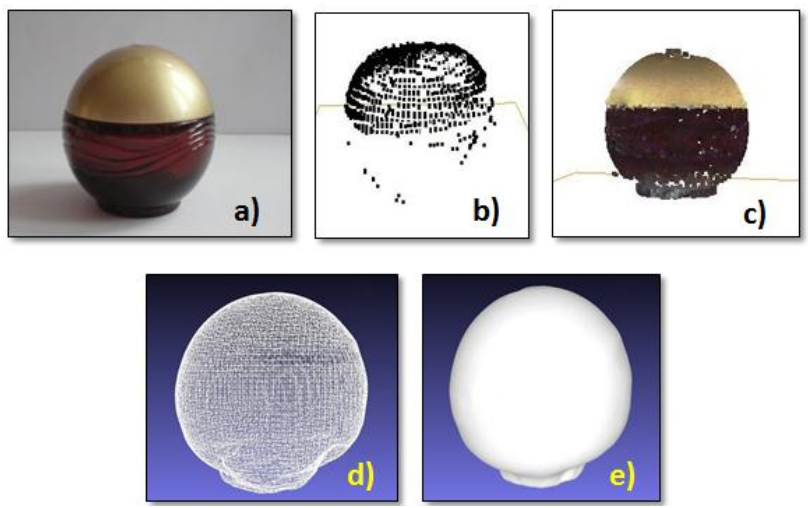

Figure 7. Glass flacon of perfumes number II: a) photo of the real objects; b) scanned cloud of points; c) scanned cloud of points after covering the object with chalk d) processed data in form of TIN surface e) 3D model

Multiple attempts of collecting the data in the form of black plastic water container showed that black objects cannot be scanned with the ground FabScan scanner. The reason is the fact that black does not absorb the laser beams (there is no reflection of the laser beam) (Fig. 8).
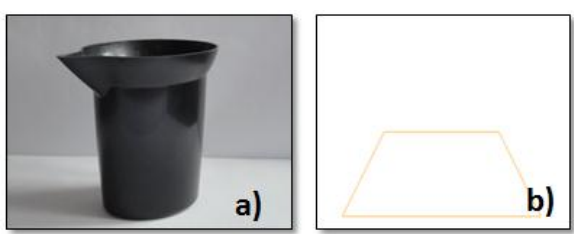

Figure 8. Plastic water container: a) photo of the real object; b) unsuccessful attempt of data collection 
The next objects chosen for the analysis are figurines made of stoneware, that are more detailed than the previous. An example figure is snail with horns made of metal springs. (Fig. 9)
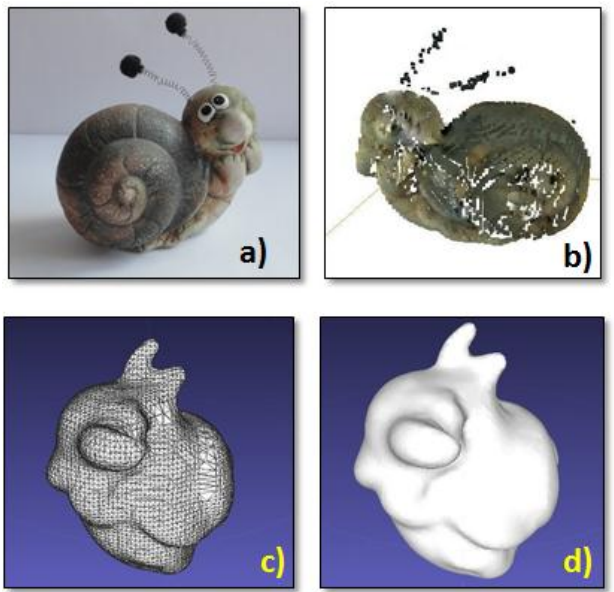

Figure 9. Snail figurette: a) photo of the real object; b) scanned cloud of points; c) processed data in form of TIN surface; d) 3D model

Analysing Figure 9, it is visible that the stone or metal springs are objects that have good reflection, because they were registered. However, the scanner hasn't done well with the detailed shapes of the figurette. The MeshLab has generated lacks in the registered cloud of points. However, the TIN surface and model are not a full mapping of the original figurette, but only its approximation. Moreover, it is worth seeing that black tentacles of the snail were not obtained in the cloud of points, i.e. in case of the black water container (Fig. 8).

An example of the ceramic mug is one of the best processes of canning. Its material and shape are ideal for collecting the data with FabScan scanner. The model ideally reflects the shape of the mug in reality (Fig. 10).
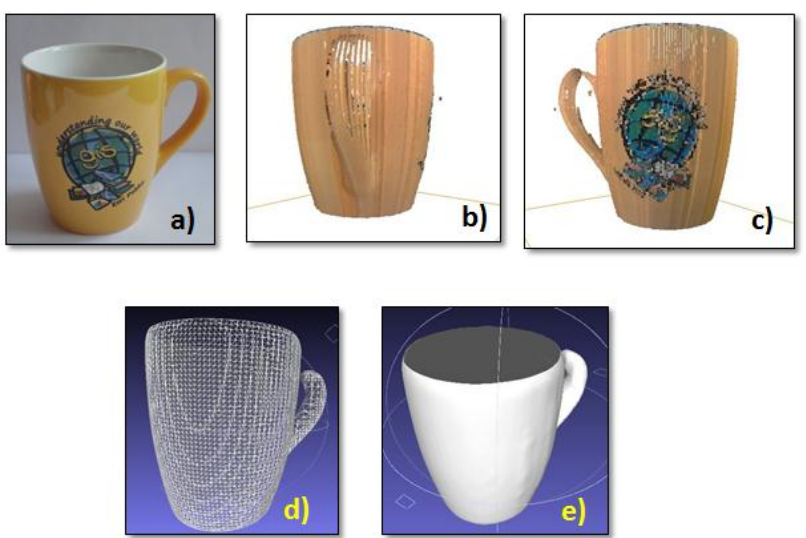

Figure 10. ceramic mug: a) photo of the object in reality; b-c) scanned cloud of points; d) processed data in form of TIN surface; e) 3D model

A scan of the paper box of a cuboid shape, and also the surface covered with glossy and smooth paper, which reflects the light, showed that this object is very problematic for the scanner.

An attempt of the data collection with the daylight reaching the scanned object was unsuccessful. Its result is presented in the Figure $11 \mathrm{~b}$, where the cloud of points is visible, it does not resemble the real object.
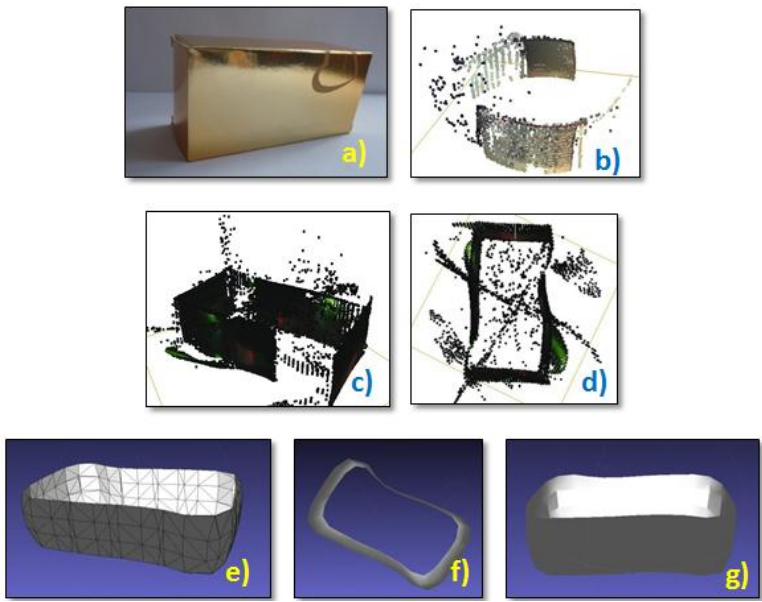

Figure 11. Paper box: a) photo of the real object; b) scanned cloud of points; c-d) scanned cloud of points without the daylight;

e) processed data in form of TIN surface $\mathrm{f}-\mathrm{g}$ ) 3D model

In the second attempt of the data collection, the daylight source was cut off. In effect, a better than the previous result was obtained, however the cloud of points is not complete. There is no upper surface of the box, the side wall are curved (Fig. 11.cd).

After clearing the cloud of points there was obtained the TIN surface and model of the (curved) side walls, that does not reflect the real object.

To summarize, on the basis of the carried research, low-budget ground laser scanner FabScan deals very well with simple shaped objects, first of all the oval ones. At the increase of the level of detailedness of the objects, their 3D models become an approximation of the original. The scanner should not be used for collection of the data from objects that have a size similar to cuboid because the device cannot do well with their processing. Moreover, it should be remembered that also objects in black cannot be scanned because the beams are absorbed, not reflected. However, the smooth and glass surfaced reflect the light negatively; they disturb the scanning process.

Table 5 presents the comparison of the values of mean errors of the accuracy analysis

\begin{tabular}{|c|c|c|}
\hline $\begin{array}{l}\text { Analyzed } \\
\text { subject }\end{array}$ & Length description & $\begin{array}{c}\text { Average } \\
\text { error } \\
{[\mathrm{mm}]} \\
\end{array}$ \\
\hline \multirow{3}{*}{$\begin{array}{l}\text { Spongiform } \\
\text { mascot }\end{array}$} & height & $\pm 0,7$ \\
\hline & $\begin{array}{l}\text { Width from the external sides of } \\
\text { the feet }\end{array}$ & $\pm 0,7$ \\
\hline & Width at the waist, with hands & $\pm 0,4$ \\
\hline \multirow{3}{*}{ Perfumes bootle } & Flacon height & $\pm 0,9$ \\
\hline & $\begin{array}{l}\text { String of the lower base of the } \\
\text { bottle }\end{array}$ & $\pm 0,5$ \\
\hline & The highest width of the bottle & $\pm 0,5$ \\
\hline \multirow{3}{*}{ Snail figurette } & $\begin{array}{l}\text { Length of the snail measured } \\
\text { from the trunk to shell }\end{array}$ & $\pm 9,0$ \\
\hline & Nose length & $\pm 5,0$ \\
\hline & Width of one horn & $\pm 2,9$ \\
\hline
\end{tabular}




\begin{tabular}{|c|l|c|}
\hline \multirow{4}{*}{ Ceramic mug } & Lower diameter & $\pm 1,0$ \\
\cline { 2 - 3 } & Upper diameter & $\pm 0,5$ \\
\cline { 2 - 3 } & Heigth & $\pm 0,3$ \\
\hline \multirow{3}{*}{ Paper box } & height & $\pm 8,7$ \\
\cline { 2 - 3 } & length & $\pm 6,8$ \\
\cline { 2 - 3 } & width & $\pm 6,4$ \\
\hline
\end{tabular}

Table 5. Comparison of the obtained average errors of the single observation in the accuracy analysis of the data collection

The obtained average errors of the single observation obtained data with comparison method measured lengths of chosen elements on the objects and models are from $\pm 0,4 \mathrm{~mm}$ to $\pm 9,0$ $\mathrm{mm}$. The largest average errors had the snail figurette in three lengths, respectively $\pm 9,0 \mathrm{~mm} ; \pm 5,0 \mathrm{~mm}$ and $\pm 2,9 \mathrm{~mm}$, for the paper box the errors were more than $\pm 6 \mathrm{~mm}( \pm 8,7 \mathrm{~mm} ; \pm$ $6,8 \mathrm{~mm} ; \pm 6,4 \mathrm{~mm})$. For the other objects, the values of the errors didn't exceed $\pm 1,0 \mathrm{~mm}$.

\section{CONCLUSIONS}

The subject of the research work was collecting the data from the low-budget ground laser scanner FabScan in the form of raw clouds of the points, from which the $3 \mathrm{D}$ models were created in effect, that reflect the real copies.

During the scanning and processing the data to the form of the three-dimensional objects (spongiform mascot, glass bottle of perfumes, figurette made of stoneware, ceramic mug, and paper box) the problems could be observed and compared, that are connected with collection, processing and data analysis. Analyzing the above-given example, the following conclusions can be made:

- Low-budget ground laser scanner FabScan has difficulties with collecting the data with shapes other than oval. Moreover, the accuracy of the cloud of points is lower when there are more details. Accuracy of the data collection with oval simple shapes (i.e. ceramic mug, glass bottle of perfumes, spongiform mascot) was obtained within limits from $\pm 0,4 \mathrm{~mm}$ to $\pm 1,0 \mathrm{~mm}$, however in objects with many details (snail figurette) or shapes of cuboids (paper box), the accuract was much more weaker, namely from $\pm 2,9 \mathrm{~mm}$ to $\pm 9,0 \mathrm{~mm}$.

- FabScan has a possibility to choose one of the forms of the resolution quality of collecting the data (resolutions: best, good, normal, poor). The decision about choosing the resolution should be dependent on the requirements of the data. Preferred type of the resolution quality would be good quality, because of the values of the horizontal resolution $(1,3 \mathrm{~mm})$ and vertical $(0,4 \mathrm{~mm})$ and scanning time (ca. 13 minutes).

- Objects with the smooth and glossy surface are hard objects because of reflecting the laser beam, in the result of which the obtained data is distorted. In such a case, objects should be covered with, e.g. chalk in spray.

- Black objects or elements of the objects in the given color are hard to scan because the black color absorbs the beams and it does not reflect them. In effect, the attempts were unsuccessful and they resulted in defective clouds of points.
- Cutting the visible light off during the scanning improves the quality of the data collection. However it makes the import of the natural colors of the real objects to 3D model impossible.

- In case of showing a reliable evaluation of the accuracy of the obtained data, there has to be carried a visual analysis of 3D models and also the comparison measurement on the models and the real object. Next, the results have to be compared because the single analysis given above are not authoritative.

Moreover, in the end, it has to be reminded that this device belongs to the Open Source. However, these types of the projects have many pros and cons. In the future, this work can be extended by the modernization of the FabScan scanner through the implementation of a larger number of camera-laser modules that would allow the registration of more covered places.

\section{ACKNOWLEDGEMENTS}

This paper has been supported by the Military University of Technology, the Faculty of Civil Engineering and Geodesy, Department of Remote Sensing and Photogrammetry as a research project 933/2016.

\section{REFERENCES}

Brockhaus F.A.: Brockhouse Encyclopedia. Wydanie 19, Mannheim, Niemcy, 1986.

Corsini M. and Ranzuglia G. Meshlab: an open-source $3 d$ mesh processing system. ERCIM News, 2008.

Engelmann F., FabScan Affordable 3D Laser Scanning of Phisical Objects, September 2011.

Lanman D. and Taubin G. Build your own $3 D$ scanner: $3 D$ photography for beginners. SIGGRAPH '09: SIGGRAPH 2009 Courses, August 2009

Kedzierski, M.; Fryskowska, 2014, A. Terrestrial and Aerial Laser Scanning Data Integration Using Wavelet Analysis for the Purpose of 3D Building Modeling. Sensors 2014, 14, 12070-12092.

Kedzierski, M., Fryskowska, A. 2015. Methods of laser scanning point clouds integration in precise $3 D$ building modelling. Measurement, 74, 221-232.

Kedzierski M., Fryskowska A., Wilinska M., 2010, Naziemny skaning laserowy obiektów inżynieryjno-drogowych (Terrestrial Laser Scanning of hydrotechnical objects), Biuletym WAT, Vol. LIX, Nr 2. 